\title{
Origaminin Matematik Dersi Öğretim Programındaki Kavram ve Kazanımlarla İlişkilendirilmesi Üzerine Bir Çalışma ${ }^{1}$
}

\author{
DOI: $10.26466 /$ opus. 834525
}

\author{
$*$ \\ Mevlüde Doğan ${ }^{*}$ - Esra Bayraktar Kurt ** \\ * Dr. Öğr. Üyesi, Ondokuz Mayıs Üniversitesi, Eğitim Fakültesi, Samsun/Türkiye \\ E-Posta: mdogan@omu.edu.tr \\ ORCID: $0000-0002-0938-3023$ \\ ** Öğretmen, MEB, Samsun/Türkiye \\ E-Posta: esra-bayraktar@hotmail.com ORCID: 0000-0002-8651-0516
}

Öz

Bu çalışmada, lisansüstü eğitim alan öğretmenler ve öğretmen adaylarının origami etkinliklerini fark ettikleri matematiksel kavramlar ve kazanımların incelenmesi amaçlanmıştır. Nitel araştırma yöntemlerinden durum çalışması ile gerçekleştirilen araştırmanın katılımcıları amaçlı örnekleme yöntemlerinden kolay ulaşılabilir örnekleme yöntemi kullanılarak belirlenmiştir. Araştırmanın örneklemi bir devlet üniversitesinde Illkögretim Matematik Öğretmenliği programına kayıtl 11 lisansüstü öğrenciden oluşmaktadır. Ortaokul Matematik Dersi Öğretim Programı'nın incelendiği derste küp ve kare piramide ait origami etkinliklerini gerçekleştirmeleri için yönergeler sunulmuş, katılimcılardan bu yönergeler doğrultusunda ortaya çıkan modelleri Ortaokul Matematik Dersi Öğretim Programı'nda mevcut olan kavram ve kazanımlarla ilişkilendirmeleri istenmiştir. Origami ile elde edilen küp ve kare piramit modellerine yönelik yazll olarak toplanan veriler nitel araştırma yöntemlerinden içerik analiz yöntemi kullanılarak analiz edilmiştir. Araştırma verilerinden elde edilen bulgulara göre küp modelinde en sık karşılaşılan kavramlar; köşegen, kare, açırtay, dikdörtgen ve dik üçgendir. Kare piramit modelinde en sık karşılaşılan kavramlar ise kare, dikdörtgen, köşegen ve açırtay olmuştur. Her iki modelde de en fazla Geometri ve ölçme öğrenme alanındaki kazanımlarla ilişkilendirmeler gerçekleştirilmiştir.

Anahtar Kelimeler: Origami, Lisansüstü öğrenciler, Matematik Dersi Öğretim Programı, Matematiksel kavramlar ve kazanımlar.

\footnotetext{
${ }^{1}$ Bu çalışma, 03-05 Ocak 2021 tarihinde Adana'da düzenlenen Online 2 nd International 5 Ocak Congress on Applied Sciences (INBAK 2021)'de sunulan bildirinin genişletilmiş halidir.
} 


\title{
A Study on Associating of Origami with the Concepts and Acquisitions in the Mathematics Curriculum
}

\begin{abstract}
In this study, it is aimed to examine the mathematical concepts and attainments that teachers and prospective teachers associate with origami activities. Participants of the study were determined by using convenience sampling. The sample of the research consists of 11 graduate students enrolled in the Primary Mathematics Teaching program at a public university. In the lesson in which the Middle School Mathematics Curriculum was examined, the participants were asked to associate the emerging models with the concepts and acquisitions in the mathematics program in line with the instructions provided for performing origami activities of the cube and square pyramid. The data collected in writing for the models obtained with origami were analysed by using content analysis method. According to the findings, the most frequently encountered concepts in the cube model are; diagonal, square, bisector, rectangle, and right triangle and in the square pyramid model are square, rectangle, diagonal and bisector. Both models have been associated with the gains in the often Geometry and measuring learning area.
\end{abstract}

Keywords: Origami, Graduate students, Mathematics curriculum, Mathematical concepts and acquisitions. 


\section{Giriş}

Hızla gelişen ve değişen dünya düzenine uyum sağlayabilmek için akıl yürütme, problem çözme ve mantık-muhakeme becerilerimizin güçlendirilmesi oldukça önemlidir. Bu becerilerin güçlendirilmesinde en önemli etken nitelikli matematik eğitimidir. Matematik eğitimi ile bireyler, fiziksel dünyayı anlamalarına destek olacak bir takım bilgi ve beceri ile donatılırlar (MEB, 2009). İnsanlar, çevrelerini saran geometrik şekil ve cisimleri tanıyabilme, iki ve üç boyutlu nesneler arasındaki ilişkileri kavrayabilme, uzamsal yetenekleri geliştirebilme ve günlük hayatta karşılaşılan basit problemleri çözebilme için geometri bilgi ve becerisine ihtiyaç duyarlar (Altun, 2008; NCTM, 2000). Bu nedenle geometri öğretimine okul programlarında oldukça önem verilmektedir. Bu tür becerilerin gelişimine yönelik önerilen eğitsel araçlardan biri de origamidir (Boakes, 2008; MEB, 2009; NCTM, 2000).

Origami, "katlanmış kâğıt" anlamına gelen Japonca bir kelimedir. Japonya'da ortaya çıkan origami sanatı ile kare kâğıt kullanılarak kesme yapmadan çeşitli nesneler oluşturulur (Lang, 1989). Klasik origami ve parçalı origami olmak üzere iki çeşidi olup, klasik origamide genellikle tek parça kâğıttan hayvan, eşya gibi nesneler yapılırken modüler origami (parçalı origami) birbirine benzeyen parçaların bir araya getirilmesiyle oluşturulur ve üç boyutlu geometrik figürler yapılmasında kullanılır (Tuğrul ve Kavici, 2002). Modern origaminin kurucusu olarak bilinen Akira Yoshizawa'nın 1920'lerde oluşturduğu tasarımlar desteklenmemiş olsa da onun çabaları sayesinde origami sanatı tüm dünyada tanınmış ve günümüze kadar gelen yeni tasarımların kaynağı olmuştur (Lang, 1989). Matematikçiler, bilim adamları ve mühendislerin de dikkatini çeken origami çeşitli bilimsel çalışmalara 1şık tutmuştur (Lang, 1989; Lang, 2009). Son yıllarda bu tür çalışmaların arttı̆̆1 ve pek çok alanda origamiden faydalanıldığı görülmektedir. Fizik profesörü Robert Lang ile bugünkü potansiyeline ulaşan origami, gerçek dünya problemlerinin çözümüne katkı sağlamaktadır. Kanser tümörlerinin tedavisinde kullanılan bazı ilaçların verimliliğinin artırılması, tıkalı damarların açılması ve güneş panellerinin yeterli inceliğe getirilerek uzay araçlarına yüklenmesi origaminin sağladığı katkılardan bazılarıdır (ITÜ̈ Çekirdek, 2016). Bu katkılar da göz önüne alındığında origaminin önemi daha da artmaktadır. 
Origami, bireylerin el-göz koordinasyonunun gelişimini sağlaması ve üç boyutlu düşünebilme yeteneğini kazandırması bakımından önemlidir (Shumakov ve Shumakov, 2000). Planlı ve sürekli bir origami eğitimi ile gerçekleşen bu katkılar bireylerin eğitiminin her aşamasında önemli olacaktır (Tuğrul ve Kavici, 2002). Bireyler bu süreçte daha sabırlı ve hoşgörülü olurken aynı zamanda düşünme becerilerinin farkına varacaktır. Origami ile farklı öğrenme ortamları sunulan bireylerin hem kendi zihinsel kavramlarını oluşturmaları, hem de bu sayede anlamlı öğrenmeyi gerçekleştirmeleri sağlanacaktır (Sezginsoy Şeker, 2016).

Araştırmacılar geometrik akıl yürütmeye elverişli olan origaminin (Arıcl, 2012; Duatepe Paksu, 2016) matematik öğretiminde kullanılmasının faydalarını ortaya koymuşlardır. Öğrencilerin matematiksel dil becerilerinin gelişimine ve geometrik kavramların anlaşılmasına fırsat sunan (Boakes, 2008; Cipoletti ve Wilson, 2004) origami, uzamsal düşünebilme (Boakes, 2009; Robichaux ve Rodrigue, 2003), iki ve üç boyutlu düşünebilme becerisini geliştirir, alan ve hacim arasında ilişki kurar (MEB, 2009). Matematiksel düşünmeyi geliştirmenin yanı sıra matematiksel kavramların anlaşılmasına da katkı yapan (Cipoletti ve Wilson, 2004; Wares, 2014) origami etkinlikleri aktif yaşantılar sağlayarak matematiksel iletişim ve grup etkileşim becerilerinin gelişimine katkıda bulunur (Brady, 2008). Öğrencilere matematiksel deneyimleri farklı bir şekilde sunan origami, kare, dikdörtgen, paralelkenar gibi çokgenlerin özelliklerinin ne olduğunu açıklamak yerine öğrencinin bu kavramları ve aralarındaki ilişkileri katlayarak kendisinin oluşturmasına olanak sağlar (Wenciker ve Flynn, 2004). Öğrencilerin geometri bilgisini geliştiren ve geometri başarısını artırmaya yardımcı olan (Arıcı ve Tutak, 2013) origami etkinlikleri problem çözme becerilerini de güçlendirmektedir (Wares, 2014; Wenciker ve Flynn, 2004).

İlgili alanyazında; öğretmen adayları ile deneysel bir araştırma yapan Akayuure, Asiedu-Addo ve Alebna (2016), origami etkinliklerinin uzamsal yetenek ve geometri bilgisini geliştirdiği sonucuna varmışlardır. "Üçgen ve Dörtgenler" konusunda yapılan origami tabanlı etkinliklerin uygulanma sürecinde öğretmen adaylarının karşılaştıkları zorlukları ve adaylara sağladığı katkılarını araştıran Hacısalihoğlu Karadeniz (2020), çalışmasında öğretmen adaylarının mesleki ve kişisel deneyim kazandıklarını tespit etmiştir. Arslan (2012) çalışmasında, origaminin matematik eğitiminde kullanımına yönelik inanç ve öz yeterlik ölçekleri geliştirmiş ve bu ölçeğin uygu- 
lanması sonucunda ilköğretim matematik öğretmen adaylarının matematik eğitiminde origami kullanılmasının faydalı olduğuna inandıkları sonucunu elde etmiştir. Öz yeterlik algıları ise orta seviyenin biraz üzerinde olarak belirlenmiştir. Sezginsoy Şeker (2016) farklı disiplin alanlarına yönelik hazırlanan origami etkinliklerine ait sınıf öğretmeni adaylarının görüsslerini incelediği çalışmasında katılımcıların origami ile öğrencilerin bilişsel becerilerinin (üç boyutlu düşünme, yaratıc düşünme ve tahmin etme vb.); duyuşsal becerilerinin (işbirlikli öğrenme ve özgüven becerisi vb.) ve psikomotor becerilerinin (parmak-kas ve elgöz koordinasyonu vb.) gelişebileceğini ifade ettikleri sonucuna ulaşmıştır. Ayrıca, origaminin matematiksel düşünceyi geliştirmesindeki yerini gösteren çeşitli çalışmalar da bulunmaktadır (Akauyuure, Asiedu-Addo ve Alebna, 2016; Arıcı ve Aslan-Tutak, 2013; Arslan, 2012; Boakes, 2009; Gür ve Kobak Demir, 2017; Tuğrul ve Kavici, 2002; Wares, 2014).

Türkiye'de farklı yıllara ait Matematik Dersi Öğretim Programları'nda yer verilen (MEB, 2009; MEB, 2018) origaminin eğitsel ve gelişimsel faydaları göz önüne alındığında özellikle matematik derslerinde kullanılabilir olduğu açıtır. Origami etkinliklerinin asıl uygulayıcısı olan öğretmen ve öğretmen adaylarının bu etkinlikleri derslerde nasıl kullanacaklarına dair bilgiler edinmeleri ve kazanımlarla ilişkilendirebilmeleri önemlidir. Gür ve Kobak Demir (2019)'da nitelikli bir öğretmenin sahip olması gereken özelliklerini araştırdığı çalışmasında alan bilgisine sahip öğretmenlerin, kavramları önceki öğrenmelerle ilişkilendirebilmede etkin, ancak matematiksel bilgileri ifade ederken farklı temsil biçimlerini (grafik, tablo, şekil vb.) kullanmada zayıf kaldıkları sonucuna ulaşmışlardır. Bununla birlikte Kozikoğlu ve Senemoğlu (2018), aday öğretmenlerin mesleğin ilk yıllarında kendi alan eğitimlerinin yetersizliklerinden, deneyim eksikliklerinden ya da öğrencilerin akademik düzeylerinin düşük olmasından dolayı öğretimi planlamada ve uygulamada bir takım güçlükler yaşadıklarını tespit etmişlerdir. Öğretim programlarındaki kazanımları öğrencilere aktaran rolde olan bugünün ve geleceğin öğretmenlerinin kişisel özelliklerinin yanı sıra mesleki ve alan bilgilerinin de geliştirilmeye ihtiyaç olduğu anlaşılmaktadır. Bu çalı̧̧malara ilave olarak, lisansüstü öğrencilerle, öğretmen ve öğretmen adaylarıyla öğretim teknolojilerine bakış açısı (Baki, Aydın Yalçınkaya, Özpınar ve Çalık Uzun, 2019), matematiksel dil becerileri (Canbazoğlu ve Tarım, 2019), öğretmen genel yeterlilikleri (Çelik, Yorulmaz ve Çokçalışkan, 
2019), matematik okuryazarlığı (Ozgen, 2019), matematik öz-yeterlilik inançları (Şahin, Gökkurt ve Soylu, 2014) üzerine araştırmalar yapılmış, ancak origami ile matematiksel kavram ve Ortaokul Matematik Dersi Öğretim Programı kazanım ilişkilendirmesine yönelik bir çalışmaya rastlanmamıştır. Farklı sınıf düzeylerindeki kazanımları farklı etkinlikler ile desteklemek öğrencilerin matematiğe karşı bakış açılarında etkili olacağından öğretmen ve öğretmen adaylarının bu anlamda farkındalık kazanmaları önem arz etmektedir. Bu bağlamda, bu çalışmanın amacı, lisansüstü eğitim alan öğretmenler ve öğretmen adaylarının origami etkinliklerinde fark ettikleri matematiksel kavramları ve kazanımlarını incelemektir.

\section{Yöntem}

\section{Araştırma Modeli}

Nitel araştırmalarda; gözlem, görüşme ve doküman analizi gibi nitel veri toplama yöntemleri kullanılarak, algilar ve olaylar doğal ortamında gerçekçi ve bütüncül bir biçimde sunulur (Yıldırım ve Şimşek, 2008). Bu araştırmada katılımcların görüşlerinin belirli açlardan derinlemesine incelenmesi amaçlandığından nitel araştırma yöntemlerinden "durum çalışması", tek bir durum için birden fazla analiz birimi söz konusu olması nedeniyle de durum çalışması desenlerinden "iç içe geçmiş tek durum deseni" (Yin, 1984) kullanılmıştır.

\section{Katılımcilar}

Araştırmanın katılımcıları seçkisiz olmayan bir örnekleme yaklaşımı olan amaçsal örnekleme yöntemlerinden kolay ulaşılabilir durum örneklemesi ile belirlenmiştir. Amaçsal örnekleme, çalışmanın amacına bağlı olarak bilgi açısından zengin durumların seçilerek derinlemesine araştırılmasına imkân tanır (Büyüköztürk vd, 2014). Nitel araştırmalarda yaygın olarak tercih edilen kolay ulaşılabilir durum örneklemesi ise genellikle diğer örnekleme yöntemlerinin kullanma olanağının bulunmadığı durumlarda tercih edilmektedir (Yıldırım ve Şimşek, 2008). Çalışmanın yürütüldüğü dönemde yaşanılan pandemi sürecinden dolayı bu yöntemin tercih edilmesi zorunluluğu oluşmuştur. Bu araştırmanın katılımcllarını 2019-2020 eğitim öğretim 
yılında bir devlet üniversitesi İlköğretim Matematik Öğretmenliği yüksek lisans programına kayıtlı lisansüstü öğrenciler ( $\mathrm{f}=11)$ oluşturmaktadır. Katılımcıların gönüllü ve origami dersi almış olmalarına özellikle dikkat edilmiştir. Bu dersin ölçüt olarak alınmasının sebebi katlama tekniklerinin bilinmesinin gerekliliğidir. Katılımcılardan altısı matematik öğretmeni, diğerleri ise öğretmen adayıdır. Katılımcların isimleri yerine aday öğretmenler (ÖA) için ÖA1, ÖA $2, \ldots$, öğretmenler (Ö) için Ö̈, Ö2, ... kodları kullanılmıştır. Burada katılımcıların öğretmen adayı ve öğretmen olarak gruplandırılmasının sebebi; origaminin matematik, geometri ve yaratıcı düşünceyle ilişkili doğası gereği her iki grubun da kendi düşünce sistemlerine göre fark ettikleri matematiksel kavramlar ve ilişkilendirdikleri kazanımları belirlemektir.

\section{Veri Toplama Aracı, Verilerin Toplanması}

Öncelikle Lisansüstü İlköğretim Matematik Programı dersi kapsamında sekiz haftalık süre içinde Ortaokul Matematik Dersi Öğretim Programı katılımcılarla birlikte detaylı olarak incelenmiştir. Bu inceleme neticesinde doğru-düzlem arasındaki ilişiki ve bu esnada ortaya çıan geometrik şekillere ilave olarak iki boyuttan üç boyuta geçerek alan-hacim arasındaki ilişkinin de kurulmasına imkân oluşturacağından küp ve kare piramit etkinliklerinin kullanımı tercih edilmiştir. Özellikle bu origami etkinliklerinin seçilmesinin bir diğer nedeni de yönergelerine çevrimiçi ulaşlabilmenin mümkün olmasıdır. Katılımcılara Küp ve Kare Piramit'e ait yönergeler Google Classroom üzerinden çevrimiçi olarak verilerek bir hafta sürede çalışmalarını tamamlamaları istenmiştir. Bu süreçte katılımcılardan etkinlikleri yönergeler doğrultusunda gerçekleştirmeleri ve akabinde elde ettikleri modellerde ve modelleri tekrar açtıklarında kâğıt yüzeyinde oluşan kat izlerinde fark ettikleri matematiksel kavramları ve ilişkilendirebildikleri Ortaokul Matematik Dersi Öğretim Programı́ndaki kazanımları doküman olarak hazırlamaları ve yine çevrimiçi olarak sisteme yüklemeleri talep edilmiştir. Araştırmanın veri kaynağı katılımcıların oluşturdukları bu dokümanlardır.

Çalışmalardan birer örnek Şekil 1'de sunulmuştur. 


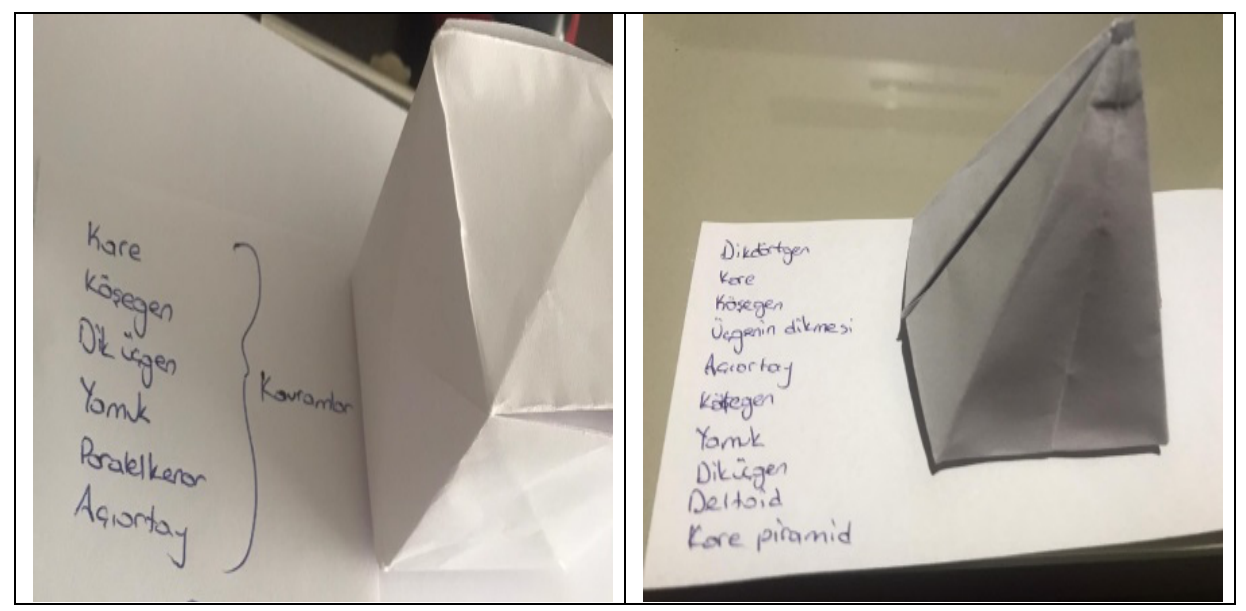

Şekil 1. Küp ve kare piramit için katılımo çalışmaları

\section{Verilerin Analizi}

$\mathrm{Bu}$ araştırmada katılımclar tarafından sunulan verilerin detaylı incelenmesi planlandığından içerik analizi kullanılmıştır. İçerik analizinde mevcut veriler benzerlikleri ve birbirleri ile ilişkilerine bağlı olarak sınıflandırılır ve yorumlanır (Yıldırım ve Şimşek, 2008). Lisansüstü öğrencilerinden oluşan katılımclar (öğretmenler ve öğretmen adayları) analiz birimleri olarak belirlenmiştir. Katılımcıların oluşturdukları veriler araştırmacılar tarafından ilk elden temin edilmiş, araştırmanın amacı doğrultusunda incelenecek ölçütler olarak küp ve kare piramit etkinliklerinde fark ettikleri matematiksel kavramlar ve kazanımlar şeklinde karar verilmiştir. Veriler detaylı bir şekilde incelenerek ayrı ayrı sınıflandırılmıştır. Ardından matematiksel kavramlar kullanım sıklıklarına göre, kazanımlar ise öğrenme alanları ve alt öğrenme alanlarına göre kategorize edilmiştir. Üçüncü olarak frekans (f) ve yüzde (\%) değerleri hesaplanmıştır. Son aşama olarak bulgular tablolarla gösterilerek yorumlanmıştır. Tablolarda öğretmenler ve aday öğretmenler tarafından fark edilmiş olan ortak kavram ve kazanımlara ait veriler koyu punto ile belirtilmiştir. 


\section{Verilerin Geçerliği ve Güvenirliği}

Nicel araştırmalara kıyasla nitel araştırmalarda geçerliği ve güvenirliği sağlamak için bir ölçütün geliştirilebilmesi eğitim ve sosyal araştırmaların en zor ve en önemli sorunlarındandır (Arastaman vd., 2018). Bununla birlikte, doğru bilgiye ulaşabilmek için gerekli önlemleri alma araştırmanın geçerliği, araştırmanın sürecini ve verilerini detaylı şekilde sunma ise araştırmanın güvenirliği için beklenen hususlardır (Yıldırım ve Şimşek, 2013). Tüm aşamalar araştırmacılar tarafından ayrı ayrı ele alınarak tablolara aktarılmış, kontrol edilmiş ve gözden kaçan bir hususun olmadığı görülmüştür. Ayrıca araştırmanın tüm aşamaları ayrıntılı olarak açıklanarak araştırmanın geçerliği ve güvenirliği artırılmaya çalışılmıştır.

\section{Bulgular}

Araştırmanın bu bölümü, katılımciların küp ve kare piramit modellerinde fark ettikleri matematiksel kavramlar ve Ortaokul Matematik Dersi Öğretim Programı'nda ilişkilendirilen kazanımlara ait verileri içermektedir.

Küp modelinde katılımcıların fark ettikleri matematiksel kavram ve bu kavramlara yönelik sayısal veriler Tablo 1'de yer almaktadır.

Tablo 1. Katılımcıların küp modeli için fark ettikleri matematiksel kavramlar

\begin{tabular}{llr}
\hline Katılımcılar & Kodlar (Matematiksel Kavramlar) & f \\
\hline Öğretmen Adayları & Açırtay, Kare, Köşegen & 5 \\
& Dikdörtgen & 4 \\
& İkizkenar dik üçgen & 3 \\
& Dik üçgen, Yamuk, Dikme, Paralelkenar & 2 \\
& Dik kesişen doğrular, Eşkenar dörtgen, Kenarortay, Orta nokta, Paralel & 1 \\
& doğru parçaları, Çakışan doğru parçaları, Doğru parçası, Özdeşlik, & \\
& Paralellik, Prizma, Tepe noktası & 6 \\
& Köşegen & 5 \\
& Kare & 4 \\
& Dikdörtgen & 3 \\
& Açırtay, Dik üçgen & 2 \\
& Dik kesişen doğrular, Paralel doğru parçaları, Dik açı, Hipotenüs, & \\
& Üçgen, Yükseklik & 1 \\
& İkizkenar dik üçgen, Kenarortay, Orta nokta, Eşkenar dörtgen, Yamuk, & 1 \\
& Açı, Deltoid, Eş kareler, Eş üģenler, İkizkenar üçgen, Kare prizma, Kenar, & \\
& Kesir, Köşe, Küp, Nokta, Simetri & \\
\hline
\end{tabular}

Tablo 1'de görüldüğü üzere katılımcıların ortak olarak fark ettikleri matematiksel kavramlar açıortay, dikdörtgen, kare, köşegen vb. olmuştur. Bu- 
nun yanı sıra öğretmen adaylarının öğretmenlerden farklı olarak belirledikleri çakışan doğru parçaları, dikme, doğru parçası, özdeşlik, paralelkenar, paralellik, prizma ve tepe noktası kavramları dikkati çekmektedir.

Kare piramit modelinde fark edilen matematiksel kavramlar ve bu kavramlara yönelik veriler ise Tablo 2'de yer almaktadır.

Tablo 2. Katılımcıların kare piramit modeli ile ulaştıkları matematiksel kavramlar

\begin{tabular}{llc}
\hline Katılımcılar & Kodlar (Matematiksel Kavramlar) & f \\
\hline Öğretmen Adayları & Dikdörtgen, Kare & 5 \\
& Açırtay, Köşegen & 4 \\
& Deltoid, Kenarortay, Tepe noktası, Yükseklik, Dikme, İkizkenar dik & 2 \\
& üçgen, Paralelkenar, Piramit, Yamuk & \\
& Açı, Dik üçgen, Eşkenar dörtgen, İkizkenar üçgen, Paralel doğru & 1 \\
& parçaları, Üçgen, Çakışı doğru parçaları, Çokgen, Kare piramit, Par- & \\
\hline alellik & Kare, Köşegen & 5 \\
& Dikdörtgen & 4 \\
& Açıortay, Dik üçgen, Eşkenar dörtgen & 3 \\
& Deltoid, İkizkenar üģgen, Tepe noktası, Üçgen, Dik açı, Dik kesişen & 2 \\
& doğrular, Eşüçgenler & \\
& Açı, Kenarortay, Paralel doğru parçaları, Yükseklik, Çakışık üçgenler, Eş & 1 \\
& kareler, Geniş açlı üçgen, Hipotenüs, Karesel bölge, Kenar, Kesişen \\
& doğrular, Köşe, Orta nokta, Üçgensel bölge & \\
\hline
\end{tabular}

Tablo 2'de öğretmen adayları ve öğretmenlerin ortak olarak fark ettikleri matematiksel kavramların kare, dikdörtgen, köşegen, açırtay vb. olduğu tespit edilmiştir. Dikme, ikizkenar dik üçgen, yamuk, çakışık doğru parçaları, çokgen, kare piramit, piramit, paralelkenar ve paralellik kavramlarının sadece öğretmen adayları tarafından fark edildiği dikkat çekmektedir. Etkinliğin sonucunda oluşması gereken kare piramit kavramının öğretmenler tarafından belirtilmemiş olması da önem arz etmektedir.

Araştırma problemine yönelik olarak Ortaokul Matematik Dersi Öğretim Programı öğrenme alanlarına ait kazanımlarla ilişkilendirilmeler incelenmiş ve aşağıdaki tablolarda sunulmuştur.

Küp modeli ile ilişkilendirildiği tespit edilen toplam 74 kazanım sınıf düzeyleri temel alınarak öğrenme alanları ve alt öğrenme alanlarına göre Tablo 3'te sunulmuştur. 
Tablo 3. Katılımcılarn küp modelini ilişkilendirdikleri kazanımlara ait bulgular

\begin{tabular}{|c|c|c|}
\hline Öğrenme Alanları & Alt Öğrenme Alanları & $\mathbf{f}$ \\
\hline \multirow[t]{3}{*}{ M.5.1. Sayılar ve işlemler } & M.5.1.1.Doğal Sayılar & 1 \\
\hline & M.5.1.3. Kesirler & 5 \\
\hline & M.5.1.4. Kesirlerle İşlemler & 2 \\
\hline \multirow[t]{4}{*}{ M.5.2. Geometri ve Ölçme } & M.5.2.1. Temel Geometrik Kavramlar ve Çizimler & 2 \\
\hline & M.5.2.2. Üçgen ve Dörtgenler & 4 \\
\hline & M.5.2.4. Alan Ölçme & 4 \\
\hline & M.5.2.5. Geometrik Cisimler & 3 \\
\hline \multirow[t]{4}{*}{ M.6.1. Sayılar ve işlemler } & M.6.1.1. Doğal Sayılarla İşlemler & 1 \\
\hline & M.6.1.3. Kümeler & 1 \\
\hline & M.6.1.5. Kesirlerle İşlemler & 5 \\
\hline & M.6.1.7. Oran & 3 \\
\hline M.6.2. Cebir & M.6.2.1. Cebirsel İfadeler & 1 \\
\hline \multirow[t]{3}{*}{ M.6.3. Geometri ve Ölçme } & M.6.3.1. Açılar & 1 \\
\hline & M.6.3.2. Alan Ölçme & 2 \\
\hline & M.6.3.4. Geometrik Cisimler & 2 \\
\hline M.6.4. Veri işleme & M.6.4.1. Veri Toplama ve Değerlendirme & 1 \\
\hline \multirow[t]{2}{*}{ M.7.1. Sayılar ve İşlemler } & M.7.1.1. Tam Sayılarla İşlemler & 1 \\
\hline & M.7.1.5. Yüzdeler & 4 \\
\hline \multirow[t]{2}{*}{ M.7.2. Cebir } & M.7.2.1. Cebirsel İfadeler & 1 \\
\hline & M.7.2.2. Eşitlik ve Denklem & 3 \\
\hline \multirow[t]{3}{*}{ M.7.3. Geometri ve ölçme } & M.7.3.1. Doğrular ve Açılar & 2 \\
\hline & M.7.3.2. Çokgenler & 4 \\
\hline & M.7.3.4. Cisimlerin Farklı Yönlerden Görünümleri & 2 \\
\hline M.8.1. Sayılar ve İşlemler & M.8.1.3. Kareköklü İfadeler & 1 \\
\hline \multirow[t]{2}{*}{ M.8.2. Cebir } & M.8.2.1. Cebirsel İfadeler ve Özdeşlikler & 1 \\
\hline & M.8.2.2. Doğrusal Denklemler & 4 \\
\hline \multirow[t]{4}{*}{ M.8.3. Geometri ve Ölçme } & M.8.3.1. Üçgenler & 4 \\
\hline & M.8.3.2. Dönüşüm Geometrisi & 1 \\
\hline & M.8.3.3. Eşlik ve Benzerlik & 1 \\
\hline & M.8.3.4. Geometrik Cisimler & 2 \\
\hline M.8.4. Veri İşleme & M.8.4.1. Veri Analizi & 2 \\
\hline M.8.5. Olasılık & M.8.5.1. Basit Olayların Olma Olasılığı & 3 \\
\hline
\end{tabular}

Katılımcıların origami ile oluşturdukları küp modelini Geometri ve Ölçme öğrenme alanında f=34, Sayılar ve İşlemler öğrenme alanında f=24, 
Cebir öğrenme alanında $\mathrm{f}=10$, Veri işleme öğrenme alanında $\mathrm{f}=3$ ve Olasılık öğrenme alanında $\mathrm{f}=3$ kazanım ile ilişkilendirdikleri görülmektedir.

Veriler detaylı incelendiğinde "Eşlik ve benzerlik" alt öğrenme alanına ait bir ilişkilendirmenin sadece öğretmen adayları, "Doğal sayılar", "Alan ölçme”, “Doğal sayılarla işlemler", “Kümeler”, “Oran”, “Cebirsel ifadeler", "Açılar", "Veri toplama ve değerlendirme", "Tam sayılarla işlemler", "Yüzdeler", "Cebirsel ifadeler", Eşitlik ve denklem", "Kareköklü ifadeler", “Cebirsel ifadeler ve özdeşlikler", ve "Doğrusal denklemler" alt öğrenme alanları ile ilişkilendirmelerin ise sadece öğretmenler tarafından gerçekleştirilmiş olduğu tespit edilmiştir.

Kare piramit modeli ile ilişkilendirildiği tespit edilen toplam 57 kazanım sınıf düzeylerine göre öğrenme alanları ve alt öğrenme alanlarına göre Tablo $4^{\prime}$ te sunulmuştur.

Katılımcıların origami ile oluşturdukları kare piramit modelini Geometri ve Ölçme öğrenme alanında $\mathrm{f}=33$, Sayılar ve İşlemler öğrenme alanında $\mathrm{f}=15$, Cebir öğrenme alanında $\mathrm{f}=9$ kazanım ile ilişkilendirdikleri görülmektedir.

Katılımcı verileri detaylı incelendiğinde "Doğal sayılar", "Eşlik ve benzerlik" ve "Geometrik cisimler" alt öğrenme alanlarına ait ilişkilendirmeler sadece öğretmen adayları, "Alan ölçme", "Doğal sayılarla işlemler", "Kümeler", "Kesirlerle işlemler", "Açlar", "Cebirsel ifadeler ve özdeşlikler" ve "Doğrusal denklemler" alt öğrenme alanları ile ilişkilendirmeler ise sadece öğretmenler tarafından gerçekleştirilmiş olduğu tespit edilmiştir. 
Tablo 4. Katılımcıların kare piramit modelini ilişkilendirdikleri kazanımlara ait bulgular

\begin{tabular}{|c|c|c|}
\hline Öğrenme Alanları & Alt Öğrenme Alanları & $\mathbf{f}$ \\
\hline \multirow[t]{3}{*}{ M.5.1. Sayılar ve işlemler } & M.5.1.1.Doğal Sayılar & 1 \\
\hline & M.5.1.3. Kesirler & 3 \\
\hline & M.5.1.4. Kesirlerle İşlemler & 1 \\
\hline \multirow[t]{4}{*}{ M.5.2. Geometri ve Ölçme } & M.5.2.1. Temel Geometrik Kavramlar ve Çizimler & 4 \\
\hline & M.5.2.2. Üçgen ve Dörtgenler & 4 \\
\hline & M.5.2.4. Alan Ölçme & 1 \\
\hline & M.5.2.5. Geometrik Cisimler & 2 \\
\hline \multirow[t]{4}{*}{ M.6.1. Sayılar ve işlemler } & M.6.1.1. Doğal Sayılarla İşlemler & 1 \\
\hline & M.6.1.3. Kümeler & 1 \\
\hline & M.6.1.5. Kesirlerle İşlemler & 1 \\
\hline & M.6.1.7. Oran & 3 \\
\hline \multirow[t]{3}{*}{ M.6.3. Geometri ve Ölçme } & M.6.3.1. Açılar & 1 \\
\hline & M.6.3.2. Alan Ölçme & 2 \\
\hline & M.6.3.4. Geometrik Cisimler & 2 \\
\hline M.7.1. Sayılar ve İşlemler & M.7.1.5. Yüzdeler & 4 \\
\hline M.7.2. Cebir & M.7.2.1. Cebirsel İfadeler & 2 \\
\hline \multirow[t]{3}{*}{ M.7.3. Geometri ve ölçme } & M.7.3.1. Doğrular ve Açılar & 2 \\
\hline & M.7.3.2. Çokgenler & 2 \\
\hline & M.7.3.4. Cisimlerin Farklı Yönlerden Görünümleri & 2 \\
\hline \multirow[t]{2}{*}{ M.8.2. Cebir } & M.8.2.1. Cebirsel İfadeler ve Özdeşlikler & 2 \\
\hline & M.8.2.2. Doğrusal Denklemler & 5 \\
\hline \multirow[t]{4}{*}{ M.8.3. Geometri ve Ölçme } & M.8.3.1. Üçgenler & 4 \\
\hline & M.8.3.2. Dönüşüm Geometrisi & 2 \\
\hline & M.8.3.3. Eşlik ve Benzerlik & 2 \\
\hline & M.8.3.4. Geometrik Cisimler & 3 \\
\hline
\end{tabular}

Küp ve Kare Piramit modelinde frekansı en yüksek olan kazanımlara ait bulgular sırasiyla Tablo 5 ve Tablo 6' da sunulmuştur. 
Tablo 5. Küp modeli ile en çok ilişkilendirilen kazanımlar

\begin{tabular}{|c|c|c|c|c|c|c|}
\hline Kazanımlar & ÖA & $\mathrm{f}$ & $\%$ & $\underline{\text { ö }}$ & $f$ & $\%$ \\
\hline $\begin{array}{l}\text { 5.2.2.1. Çokgenleri isimlendirir, oluşturur ve temel } \\
\text { elemanlarını tanır. }\end{array}$ & $\begin{array}{l}\mathrm{ÖA}_{1,}, \ddot{O ̈ A}_{3}, \\
\mathrm{OHA}_{4,} \mathrm{ÖA}_{5}\end{array}$ & 4 & 80 & $\begin{array}{l}\ddot{\mathrm{O}}_{1,}, \ddot{\mathrm{O}}_{2}, \\
\ddot{\mathrm{O}}_{4}, \ddot{\mathrm{O}}_{6}\end{array}$ & 4 & 66.7 \\
\hline $\begin{array}{l}\text { 5.2.2.2. Açılarına ve kenarlarına göre üçgenler oluştu- } \\
\text { rur, oluşturulmuş farklı üçgenleri kenar ve açı özellik- } \\
\text { lerine göre sınıflandırır. }\end{array}$ & $\mathrm{ÖA}_{1}, \mathrm{ÖA}_{4}$ & 2 & 40 & $\begin{array}{l}\ddot{\mathrm{O}}_{1}, \quad \ddot{\mathrm{O}}_{2}, \\
\ddot{\mathrm{O}}_{5}, \ddot{\mathrm{O}}_{6}\end{array}$ & 4 & 66.7 \\
\hline $\begin{array}{l}\text { 5.2.2.3. Dikdörtgen, paralelkenar, eşkenar dörtgen ve } \\
\text { yamuğun temel elemanlarını belirler ve çizer. }\end{array}$ & ÖA 1 , ÖA 5 & 2 & 40 & $\begin{array}{ll}\ddot{\mathrm{O}}_{2} & \ddot{\mathrm{O}}_{4}, \\
\ddot{\mathrm{O}}_{6} & \end{array}$ & 3 & 50 \\
\hline $\begin{array}{l}\text { 5.2.5.1. Dikdörtgenler prizmasını tanır ve temel } \\
\text { elemanlarını belirler. }\end{array}$ & $\begin{array}{l}\text { ÖA }_{1} \\
\text { ÖA }\end{array}$ & 3 & 60 & $\begin{array}{ll}\ddot{\mathrm{O}}_{1,} & \ddot{\mathrm{O}}_{4,} \\
\ddot{\mathrm{O}}_{5} & \end{array}$ & 3 & 50 \\
\hline $\begin{array}{l}\text { 6.3.4.2. Verilen bir hacim ölçüsüne sahip farklı dik- } \\
\text { dörtgenler prizmalarını birim küplerle oluşturur, } \\
\text { hacmin taban alanı ile yüksekliğin çarpımı olduğunu } \\
\text { gerekçesiyle açıklar. }\end{array}$ & $\mathrm{ÖA}_{2}, \mathrm{ÖA}_{5}$ & 2 & 40 & $\begin{array}{l}\ddot{\mathrm{O}}_{1}, \quad \ddot{\mathrm{O}}_{2}, \\
\ddot{\mathrm{O}}_{4}, \ddot{\mathrm{O}}_{5}\end{array}$ & 4 & 66.7 \\
\hline $\begin{array}{l}\text { 7.3.2.3. Dikdörtgen, paralelkenar, yamuk ve eşkenar } \\
\text { dörtgeni tanır; açı özelliklerini belirler. }\end{array}$ & ÖA5 & 1 & 20 & $\begin{array}{l}\ddot{\mathrm{O}}_{1,}, \ddot{\mathrm{O}}_{2}, \\
\ddot{\mathrm{O}}_{4}, \ddot{\mathrm{O}}_{5}\end{array}$ & 4 & 66.7 \\
\hline $\begin{array}{l}\text { 7.3.4.1. Üç boyutlu cisimlerin farklı yönlerden iki } \\
\text { boyutlu görünümlerini çizer. }\end{array}$ & $\begin{array}{l}\mathrm{ÖA}_{1}, \quad \mathrm{ÖA}_{2}, \\
\text { ÖA }_{4}, \ddot{O}_{5}\end{array}$ & 4 & 80 & $\begin{array}{ll}\ddot{\mathrm{O}}_{1,} & \ddot{\mathrm{O}}_{2}, \\
\ddot{\mathrm{O}}_{4} & \end{array}$ & 3 & 50 \\
\hline $\begin{array}{l}\text { 7.3.4.2. Farklı yönlerden görünümlerine ilişkin çizim- } \\
\text { leri verilen yapıları oluşturur. }\end{array}$ & $\begin{array}{ll}\mathrm{ÖA}_{2}, & \mathrm{ÖA}_{3}, \\
\text { ÖA5 } & \end{array}$ & 3 & 60 & $\begin{array}{ll}\ddot{\mathrm{O}}_{1,} & \ddot{\mathrm{O}}_{2}, \\
\ddot{\mathrm{O}}_{4} & \end{array}$ & 3 & 50 \\
\hline
\end{tabular}

Tablo 5 incelendiğinde küp modelinde en yüksek frekans değerine sahip olan kazanımların katılımcılar tarafından ilişkilendirilme sıklıklarının birbirine yakın olduğu görülmekle birlikte "7.3.2.3. Dikdörtgen, paralelkenar, yamuk ve eşkenar dörtgeni tanır; açı özelliklerini belirler." kazanımının ise sadece bir öğretmen adayı tarafından ilişkilendirilmiş olması dikkat çekmektedir.

Tablo 6. Kare piramit modeli ile en çok ilişkilendirilen kazanımlar

\begin{tabular}{|c|c|c|c|c|c|c|}
\hline Kazanımlar & ÖA & $\mathrm{f}$ & $\%$ & $\underline{\ddot{0}}$ & $\mathrm{f}$ & $\%$ \\
\hline $\begin{array}{l}\text { 5.2.2.1. Çokgenleri isimlendirir, oluşturur ve temel } \\
\text { elemanlarını tanır. }\end{array}$ & $\mathrm{ÖA}_{4}, \mathrm{ÖA}_{5}$ & 2 & 40 & $\begin{array}{ll}\ddot{\mathrm{O}}_{1,} & \ddot{\mathrm{O}}_{2}, \\
\ddot{\mathrm{O}}_{4} & \end{array}$ & 3 & 50 \\
\hline $\begin{array}{l}\text { 8.3.4.1. Dik prizmaları tanır, temel elemanlarını } \\
\text { belirler, inşa eder ve açınımını çizer. }\end{array}$ & $\mathrm{ÖA}_{4}, \mathrm{ÖA}_{5}$ & 2 & 40 & $\begin{array}{l}\ddot{\mathrm{O}}_{1,}, \ddot{\mathrm{O}}_{4,} \\
\ddot{\mathrm{O}}_{5}, \ddot{\mathrm{O}}_{6}\end{array}$ & 4 & 66.7 \\
\hline $\begin{array}{l}\text { 8.3.4.5. Dik piramidi tanır, temel elemanlarını belirler, } \\
\text { inşa eder ve açınımını çizer. }\end{array}$ & $\begin{array}{l}\mathrm{Ö}_{1}, \\
\mathrm{ÖA}_{5}\end{array}$ & 3 & 60 & $\begin{array}{ll}\ddot{\mathrm{O}}_{2} & \ddot{\mathrm{O}}_{4} \\
\ddot{\mathrm{O}}_{5} & \end{array}$ & 3 & 50 \\
\hline
\end{tabular}

Tablo 6'da kare piramit modelinde en yüksek frekans değerine sahip olan kazanımların katılımcılar tarafından ilişkilendirilme sıklıklarının birbirine yakın olduğu görülmektedir. 


\section{Tartışma ve Sonuç}

Bireysel farklılıkları dikkate alan öğretim programlarında farklı sınıf düzeylerinde sarmal bir yaklaşımla tekrar eden kazanımlar eğitim sürecinde hayati önem taşımaktadır (MEB, 2018). Öğrenme-öğretme sürecine etki eden faktörler aynı zamanda programı uygulama sürecinde de etkendir. Öğrencilerin sahip oldukları öğrenmeleri üzerine yenilerini yapılandırmak ve nitelikli öğrenmeyi gerçekleştirmek için öğretmen ve öğretmen adaylarının öğretim programı içinde yer alan tüm öğrenme alanlarındaki kavram ve kazanımlara vakıf olmaları, öğrenme süreci içinde uygun yöntem ve yaklaşım tercihleri (MEB, 2018), geniş bakış açısına sahip olmaları önem arz etmektedir. Bu gerekçeden yola çıkılarak bu araştırmada lisansüstü eğitim alan öğretmenler ve öğretmen adaylarının origami etkinliklerinde fark ettikleri matematiksel kavramlar ve kazanımlar incelenmiştir.

Matematiksel kavram için elde edilen bulgular dikkate alındığında, katılımcıların küp modelinde fark ettikleri matematiksel kavramların köşegen, kare, açıortay, dikdörtgen, dik üçgen ve kare piramit modelinde ise kare, dikdörtgen, köşegen ve açıortay olduğu görülmüştür. İki boyuttan üç boyuta geçtiğimiz katlama süreci içerisinde belirli aşamaların aynı olması, kare kâğıttan önce iki eş dörtgen elde edilmesi ve ardından iki eş üçgenin oluşturulması neticesinde oluşan köşegenlerin bu ortak kavramların sıklıkla fark edilme nedeni olabilir. Nitekim Boz (2015), yedinci sınıf öğrencilerinin dikdörtgen, paralelkenar, küp vb. gibi geometrik kavramları kendi yaptıkları katlamalar ile elde ettiklerini tespit etmiştir. Kâğt katlayarak modele ulaşılırken nokta, doğru, açı, deltoid, açıortay, simetri ekseni, kare... gibi geometrik kavramlar şekil üzerinde oluştuğundan (MEB, 2009; Wenciker ve Flynn, 2004) Öklid geometrisinin tam anlamılla öğrenilmesine katkı sağlamakta (MEB, 2009) ve bireyin Öklid geometrisinin birçok kavramını tanımasına yardımcı olmaktadır (Boz, 2015).

Lisansüstü eğitim alan öğretmenler ve öğretmen adaylarının fark ettikleri kavramlarda ortak olan kavramların yanı sıra farklılık gösteren kavramların olduğu da dikkat çekmektedir. Öğretmen adaylarının daha ziyade küp ve kare piramite ait model üzerinde göze görünen temel kavramlara odaklandıkları, öğretmenlerin ise bu kavramların yanı sıra etkinlik kâğıdı açıldığında ortaya çıkan kavramları da fark ettikleri söylenebilir. İki modelin sonucunda farklılaşan bu kavramlar öğretmenlerin mesleki tecrübeleri kay- 
naklı olabilir. Benzer şekilde, Canbazoğlu ve Tarım (2019), sınıf öğretmenleri ve sınıf öğretmen adayları ile matematiksel dil becerilerine ilişkin farkındalıkları üzerine yaptıkları çalışmada, öğretmen adaylarının İlkokul Matematik Dersi Öğretim Programı'nda yer alan matematiksel yetkinlik anlamında yeterince bilgi sahibi olmadıkları görülmüş̧ür. Yine Ozgen (2019), öğretmen ve öğretmen adayları ile matematik okur-yazarlığ 1 üzerine yaptığ çalışmasında öğretmenlerin öğretmen adaylarına göre daha başarılı olduğu sonucu ulaşmıştır.

Çalışmada dikkati çeken bir durum da katılımcların origami etkinliklerinde fark etmedikleri kavramların mevcut olmasıdır. Küp ve kare piramit modeli için hacim, ayrit, boyut, alan, çevre, taban alanı, dik piramit, dik prizma ve ters açlar fark edilemeyen matematiksel kavramlardır. Bu kavramların fark edilememe sebebinin iki ve üç boyutlu nesneler arasındaki ilişki kurmada yaşanılan güçlükler, deneyimsizlik ya da dikkat eksikliğinden kaynaklı olabileceği düşünülmektedir.

Katılımcıların Ortaokul Matematik Dersi Öğretim Programı kazanımları ile ilişkilendirmeleri neticesinde elde edilen bulgular dikkate alındığında tüm sınıf düzeylerinde mevcut olan toplam 215 kazanım içinden küp modeli için 74 kazanım ve Kare piramit modeli için ise 57 kazanım ile ilişkilendirdikleri belirlenmiştir. Çalışmadan elde edilen bu bulgulara dayalı olarak gerçekleştirilmiş olan küp ve kare piramit modellerinin kazanım ilişkilendirmesinde ilk sıralarda Geometri ve Ölçme öğrenme alanına ait kazanımların yer aldığı görülmektedir. Bunun sebebi olarak katlama başlangıcında ve devamında geometrik şekillerin görünür olması, ders kitaplarındaki origami etkinliklerinin geometri ile ilgili olmasından kaynaklandığı düşünülmektedir. Alanyazındaki Akayuure vd. (2016); Gür ve Kobak Demir (2017); Hacısalihoğlu Karadeniz (2020) çalışmaları bu sonucu destekler niteliktedir. Yine, oluşturulan modeller ile fark edilen kavram ve ilişkilendirilen kazanımlarının sıklıkla Geometri ve Ölçme öğrenme alanından olması geometri ve origami arasındaki ilişkinin bir sonucu olduğu düşünülmektedir. Origaminin geometri ile ilişkisi ve geometri başarısı üzerinde olumlu etkilerini tespit eden (Aricı ve Tutak, 2013; Boakes, 2009; Cipoletti ve Wilson, 2004; Wares, 2014) araştırmalar mevcuttur.

Bununla beraber daha detaylı ve derinlemesine bir inceleme ve akıl yürütmenin neticesinde tespit edilen Sayılar ve işlemler alt öğrenme alanı ile ilişkilendirilen kazanımların sayısı da gözden kaçırılmaması gereken bir 
durumdur. Bir bütün üzerinde katlama neticesinde birbirine eş ve benzer parçaların oluşması, bütün ve parça arasındaki ilişkiyi çağrıştırmaktadır. Bunun sonucu olarak oran, kesir ve kesirlerle işlemler alt öğrenme alanına ait kazanımlarla ilişkilendirmelerin gerçekleştirilmiş olduğu düşünülmektedir. Nitekim Akan (2008)'de yaptığı tez çalışmasında origami ile desteklenmiş kesir örneklerinde öğrencilerin parça bütün arasında ilişki kurmada başarılı oldukları sonucuna ulaşmış, origaminin Sayılar ve işlemler öğrenme alanında da kullanılabilirliğini göstermiştir. Bununla birlikte katlama sayısının artmasıyla kâğıt yüzeyinde oluşan alt bölümler arasında doğrudan bir ilişki söz konusudur. Bu ilişki origaminin 8. sınıf Sayılar ve İşlemler öğrenme alanı Üslü İfadeler ve Köklü İfadeler alt öğrenme alanında da kullanılabilirliğinin açık ve net göstergesidir.

Sonuç olarak yaparak yaşayarak kalıcı öğrenmeyi sağladığı için tüm öğrenme alanlarında öğretmen adaylarının, öğretmenlerin ve öğrencilerin uygun origami etkinliklerini kullanmaları fayda sağlayacaktır (Hacısalihoğlu Karadeniz, 2017). Bu gerekçeden hareketle öğretmen adaylarından Ortaokul Matematik Dersi Öğretim Programı'ndaki farklı sınıf düzeylerinde yer alan kazanımlar için uygun origami etkinliklerini araştırılmaları beklenmelidir. Öğrencilerinin mevcut sınıf düzeylerinden önceki sınıf düzeylerine ait kazanımlara sahip olmaları derse hazır bulunuşlarında ve öğrenmenin niteliğinde önem arz ettiğinden öğretmen ve öğretmen adaylarının bu konuda kendilerini sorumlu hissetmeleri, varsa, eksikliklerini telafi etmeleri beklenmelidir. Bu durum dersin verimliliğini ve niteliğini artıracaktır. Ancak dikkate alınması gereken bir durum çalışmanın sonucunda elde edilen öğretmen adaylarının Ortaokul Matematik Dersi Öğretim Programı'nı kazanımlarla ilişkilendirmede öğretmenlerden daha az performanslı olmalarıdır. Bu sonucun olası sebeplerinin araştırılacağı bir başka çalışma planlanabilir.

\section{Araştırma Etiği}

Bu araştırmaya başlamadan önce Ondokuz Mayıs Üniversitesi Sosyal ve Beşeri Bilimler Etik Kurulu Başkanlığına başvuru yapılmış, etik kurul başkanlığının 29.05.2020 tarihinde gerçekleştirdiği toplantısında 2020/309 karar sayısı ile araştırmanın etik açıdan uygun olduğuna karar vermiştir. Araştırmada alıntılar bilimsel kurallara uygun olarak yapılmış olup, araştırma gönüllü olan katılımcılarla yürütülmüş̧ür. 
EXTENDED ABSTRACT

\section{A Study on Associating of Origami with the Concepts and Acquisitions in the Mathematics Curriculum \\ Mevlüde Doğan- Esra Bayraktar Kurt \\ Ondokuz Mayıs University-MONE}

Individual differences are taken into account in teaching programs. The learning outcomes that spirally repeat at different grade levels are vital in the education process (MoNE, 2018). Factors affecting the learningteaching process are also effective in the implementation process of the program. It is important for teachers and pre-service teachers' to have the concept and learning outcomes, appropriate teaching methods and techniques (MoNE, 2018), and wide perspectives in the curriculum in order to gain new knowledge to their students and to realize qualified learning. Considering the educational and developmental benefits of origami, which is included in different years the mathematics curriculium, it is understood that it should be applied especially in mathematics lessons.

Teachers and pre-service teachers are the main practitioners of origami activities. Therefore, it is important to get information on how to use these activities in lessons and to associate with the learning outcomes for them. Gür and Kobak Demir (2019), at their study investigating the characteristics that a qualified teacher should have, although concluded that teachers with content knowledge are effective in associating concepts with previous learning are weak in using different forms of representation (graphic, table, figure etc.) while expressing mathematical knowledge. Further, Kozikoğlu and Senemoğlu (2018) found that preservice teachers' experienced some difficulties in planning and implementing education due to the inadequacy of their own field education, lack of experience in the first years of the profession, and the low academic level of their students. In addition to the personal characteristics of today's and future teachers, who have a role in transferring the learning outcomes to students, the professional and field knowledge should 
be also developed. Additionaly, there has been variety studies investigating teacher and prospective teachers' in the literature on their perspective on teaching technologies (Baki, Aydın Yalçınkaya, Özpınar and Çalık Uzun, 2019), mathematical language skills (Canbazoğlu and Tarım, 2019), teacher general competencies (Çelik, Yorulmaz and Çokçalışkan, 2019), mathematics literacy (Ozgen, 2019), and mathematics self-efficacy beliefs (Şahin, Gökkurt and Soylu, 2014). By reviewing the related literature, no studies have been investigating opinions of teachers and preservice teachers' about to associate origami with mathematical concepts and learning outcomes in mathematics curriculum. Supporting the learning outcomes at different grade levels with different activities will be effective on students' perspectives towards mathematics. Therefore, the awareness in this sense of teachers and pre-service teachers' is important. In this context, in this current study were examined the mathematical concepts and acquisitions that teachers and pre-service teachers' associate with origami activities.

The case study pattern which is one of the qualitative research methods has been used in the research. This qualitative study was conducted with 11 (6 teacher, 5 pre-service teacher) graduate students who Elementary Mathematics Teaching master's program at a state university in 2019-2020 academic year. To determine the participants, convenience sampling were used. Data was collected via the online platform due to being in the process of the pandemic. The qualitative data obtained in the study were analyzed through the content analysis method.

The first four mathematical concepts in the cube model frequently noticed by the participants were the concepts diagonal, square, bisector and rectangle, respectively. Another interesting result that draws attention in the study is that the concepts of strut, parallelogram, overlapping line segments, line segment, identities, prism and peak point, determined only of pre-service teachers.

Moreover, similarly the mathematical concepts in the cube model, they focused on also the same mathematical concepts (diagonal, square, bisector and rectangle) in the square pyramids. Another interesting result that draws attention in the study is that the concepts of coincident line segments, polygon, perpendicular, isosceles triangle, square pyramid, parallelogram, parallelism, pyramid, trapezium, determined only of 
pre-service teachers. Still another result revealed in the study is that the squuare pyramid concept, which should be formed as a result of the activity, haven't noticed by teachers.

In the light of the findings of the research in the cube model, it was seen that associate with gains which $\mathrm{f}=34$ gains in the geometry and measurement, $\mathrm{f}=24$ gains in the numbers and operations, $\mathrm{f}=10$ in the algebra, $f=3$ gains in the data processing and $f=3$ gains in the probability. Similarily, it was determined that the participants associated the square pyramid model with geometry and measurement $f=33$ gains, numbers and operations $\mathrm{f}=15$ gains, and algebra $\mathrm{f}=9$ gains.

The frequency of associations of the gains, which has the highest frequency, is close to each other, in both models. However, "7.3.2.3. Students can recognizes rectangle, parallelogram, trapezium and rhombus; determines the angle properties." assosicated by only single pre-service teacher' in cube model.

As a result, the study reveals that at the cube and square pyramid can noticed the mathematics concepts and gains of participants'. Therefore, this models could be diversified and used also with students at university levels. As this activities can be implemented in different learning outcomes low cost and easily, it could be supportting for mathematics conceps and gains in different levels to learn it. In addition, in the schools and in particular education faculties because the teachers and pre-service teachers' have qualification in teaching in the mathematics concepts and gains and using, is needed. It is suggested that origami activities used mathematics education, should be more releated in mathematics concepts and gains. Based with the results, it was recommended that preservice teachers' should be informed about the benefits of origami activities.

\section{Kaynakça / References}

Akan Sağsöz, D. (2008). İlköğretim 6. Simflardaki kesirler konusunun origami yardimuyla öğretimi. Yayımlanmamış Yüksek lisans Tezi. Atatürk Üniversitesi. Fen Bilimleri Enstitü, İlköğretim Ana Bilim Dalı, Erzurum.

Akayuure, P., Asiedu-Addo, S. K. and Alebna, V. (2016). Investigating the effect of origami instruction on pre-service teachers' spatial ability and geometric 
knowledge for teaching. International Journal of Education in mathematics, Science and Technology, 4(3), 198-209. http:// doi:10.18404/ijemst.78424.

Altun, M. (2008). Matematiköğretimi. (6. Baskı). Bursa: Erkam Matbaacilık.

Arastaman, G., Öztürk Fidan, İ. ve Fidan, T. (2018). Nitel araştırmalarda geçerlik ve güvenirlik: Kuramsal bir inceleme. YYü Eğitim Fakültesi Dergisi, 15(1), 3775. dx.doi.org/10.23891/efdyyu.2018.61.

Arıc, S. (2012). Origami Temelli Öğretimin 10. Sinıf Öğrencilerinin Uzamsal Görselleştirme, Geometri Başarısı ve Geometrik Akıl Yürütmeleri Üzerine Etkisi. Yayınlanmamış Yüksek Lisans Tezi. Boğaziçi Üniversitesi, Fen Bilimleri Enstitü, Ortaöğretim Fen ve Matematik Alanlar Eğitimi Ana Bilim Dalı, İstanbul.

Arıc, S. ve Aslan Tutak, F. (2013). Using origami to enhance geometric reasoning and achievement. Paper presented at the Eighth Congress of European Research in Mathematics Education (CERME 8), Antalya.

Arslan, O. (2012). Investigating beliefs and perceived self-efficacy beliefs of prospective elementary mathematics teachers towards using origami in mathematics education. (Yayımlanmamış doktora tezi). Ortadoğu Teknik Üniversitesi, Sosyal Bilimler Enstitüsü, Fen ve Matematik Alanlar Eğitimi Ana Bilim Dalı, Ankara.

Baki, A., Aydın Yalçınkaya, H., Özpınar, I. ve Çalık Uzun, S. (2009). İlköğretim matematik öğretmenleri ve öğretmen adaylarının öğretim teknolojilerine bakışlarının karşılaştırılması. Turkish Journal of Computer and Mathematics Education, 1(1), 67-85.

Boakes, N. (2008). Origami-mathematics lessons: Paper folding as a teaching tool. Mathitudes, 1(1), 1-9.

Boakes, N. (2009). Origami-Mathematics lessons: Researching its impact and influence on mathematical knowledge and spatial ability of students. 04 Nisan 2020 tarihinde http://math.unipa.it/ grim/21_project/Boakes69-73.pdf adresinden erişildi.

Boz, B. (2015). İki boyutlu kâğıtlardan üç boyutlu origami küpüne yolculuk. Araştırma Temelli Etkinlik Dergisi (ATED), 5(1), 20-33.

Brady, K. M. (2008). Using paper-folding in the primary years to promote student engagement in mathematical learning. 31st Annual Conference of the Mathematics Education Research Group of Australasia (s.77-83). MERGA Inc.

Büyüköztürk, Ş., Kılıç Çakmak, E., Akgün, Ö. E., Karadeniz, Ş. ve Demirel, F. (2014). Bilimsel araştırma yöntemleri. (16. Baskı). Ankara: Pegem Akademi. 
Canbazoğlu, H. B. ve Tarım, K. (2019). Sınıf öğretmenlerinin ve sınıf öğretmeni adaylarının matematiksel dil becerilerine ilişkin farkındalıkları. İlköğretim Online, 18(4), 1919-1937. doi:10.17051/ilkonline.2019.639365.

Cipoletti, B. and Wilson, N. (2004). Turning origami into the language of mathematics. Mathematics Teaching in the Middle School, 10(1), 26-31.

Çelik, Ö., Yorulmaz A. ve Çokçalışkan H. (2019). Öğretmen genel yeterlikleri açısından sınıf öğretmenleri ve öğretmen adaylarının kendilerini değerlendirmeleri. Eskişehir Osmangazi Üniversitesi Sosyal Bilimler Dergisi, 20(Özel sayı), 203-215. dor: 10.17494/ogusbd.548342

Duatepe Paksu, A. (2016). Kâğıt katlama yöntemiyle dörtgenlerin incelenmesi. Araştirma Temelli Etkinlik Dergisi (ATED), 6(2), 80-88.

Gür, H. ve Kobak Demir, M. (2017). Geometry Teaching via origami: The views of secondary mathematics teacher trainees. Journal of Education and Practice, $8(15), 65-71$.

Gür, H. ve Kobak Demir, M. (2019). Matematik öğretmenlerinin öğretim profillerinin belirlenmesi. Uluslararası Eğitim Bilim ve Teknoloji Dergisi, 5(2), 67-105.

Hacısalihoğlu Karadeniz, M. (2017). Kâğıt katlama yöntemi ile matematik öğretimi. İköğretim Online, 16(2), 663-692. doi: 10.17051/ilkonline.2017.304726.

Hacısalihoğlu Karadeniz, M. (2020). Origami tabanlı öğretim uygulamalarının öğretmen adaylarına katkıları ve karşılaşılan zorluklar: Üçgen ve dörtgenler. OPUS-Uluslararası Toplum Araştırmaları Dergisi, 15(24), 2584-2614. https://doi.org/10.26466/opus.651290.

İTÜ Çekirdek. (2016, 18 Temmuz). Origami sanatı modern teknolojiye nasıl ilham veriyor? [Blog yazısı]. Erişim adresi: https://blog.itucekirdek.com/origamisanati-modern-teknolojize-nasil-ilham-veriyor

Kozikoğlu, İ. ve Senemoğlu, N. (2018). Mesleğe yeni başlayan öğretmenlerin karşılaştıkları güçlükler: Nitel bir çözümleme. Eğitimde Nitel Araştırmalar Dergisi, 6(3), 341-371. doi:10.14689/issn.2148-2624.1.6c3s16m.

Lang, R. J. (Winter, 1989). Origami: Complexity increasing. Engineering ve Science, 1623.

Lang, R. J. (2009). Mathematical methods in origami design. Bridges 2009: Mathematics, Music, Art, Architecture, Culture, 13-20.

Milli Eğitim Bakanlı̆̆ [MEB]. (2009). Illköğretim matematik dersi 6-8. sinfflar öğretim programı ve klavuzu. Ankara: MEB Yayınevi.

Milli Eğitim Bakanlı̆̆ [MEB]. (2018). Matematik dersi öğretim programı (1.-4. ve 5.-8. simiflar). Ankara: MEB Yaymevi. 
National Council of Teachers of Mathematics [NTCM]. (2000). Principles and standarts for school mathematics. Reston, VA: National Council of Teachers of Mathematics.

Ozgen, K. (2019). Problem posing skills for mathematical literacy: The sample of teachers and pre-service. Eurasian Journal of Educational Sciences, 84, 179-212. doi:10.14689/ejer.2019.84

Robichaux, R. R. and Rodrigue, P. R. (2003). Using origami to promote geometric communication. Mathematics Teaching in the Middle School, 9(4), 222-229. doi.org/10.5951/MTMS.9.4.0222

Sezginsoy Şeker, B. (2016). Sınıf öğretmeni adayları tarafından oluş̧turulan origami etkinliklerinin değerlendirilmesi. Turkish Studies, 11(3), 1991-2008.

Shumakov, K. and Shumakov, Y. (2000). Left brain and right brain at origami training. 04 Nisan 2020 tarihinde https://www.oriland.com/oriversity/lecture.php? category=benefitsveID=02\#Intro adresinden erişildi.

Şahin, Ö., Gökkurt, B. ve Soylu, Y. (2014). Öğretmenlerin ve öğretmen adaylarının matematik öğretimi öz-yeterlik inançlarının karşılaştırılması. Dicle Üniversitesi Ziya Gökalp Ĕ̈itim Fakültesi Dergisi, 22, 120-133.

Tuğrul, B. ve Kavici, M. (2002). Kâğıt katlama sanatı ve öğrenme. Pamukkale Üniversitesi Ĕ̆itim Fakültesi Dergisi, 1(11), 1-17.

Wares, A. (2014). Problem solving through paper folding. Australian Senior Mathematics Journal, 28(2), 60-63.

Wenciker, B. and Flynn, P. (2004, 30 July-1 August). Modular origami in the mathematics classroom. Bridges Conference Proceedings: Mathematical Connections in Art, Music and Science, 293-296, Winfield, Kansas, USA.

Yıldırım, A. ve Şimşek, H. (2008). Sosyal bilimlerde nitel araştırma yöntemleri. (6. Basım). Ankara: Seçkin Yayıncilı.

Yin, R. (1984). Case study research: design and methods. (3. Basim). California: Sage Publications.

\section{Kaynakça Bilgisi / Citation Information}

Doğan, M. ve Bayraktar Kurt, E. (2021). Origaminin matematik dersi öğretim programındaki kavram ve kazanımlarla ilişkilendirilmesi üzerine bir çalışma. OPUS-Uluslararası Toplum Araştırmaları Dergisi, 18(41), 3237-3259. DOI: 10.26466/opus.834525. 